\section{Consequences of nuclear warfare}

SIR - Nature has from time to time criticized individual scientists and groups of scientists for their activities in behalf of peace and disarmament, especially in respect to nuclear weapons. But even this back-ground left us unprepared for the tone and content of Vera Rich's article (28 October 1982, p. 769). Basing herself on an article by $E$. Teller published in Reader's Digest, she endeavours to represent nuclear war as somehow survivable and thus perhaps not so different from preHiroshima warfare. She speaks of a "swift return to quasi-normality after nuclear bombardment". Referring to Teller's Reader's Digest article she writes that " $[\mathrm{He}]$ attempts to refute some of the more fantastic myths of what nuclear war would entail. [He quotes] instances from Hiroshima and Nagasaki: 'bridges open ... a day after the blast, trains ran on the second day, streetcars. . . on the third"'.

Her terminology "fantastic myths" betrays her own outlook. It betrays also a failure to understand some indisputable and obvious aspects of the situation. Now, unlike in the days of Hiroshima and Nagasaki, huge numbers of nuclear bombs could saturate a whole country. This is the age of the new word "overkill". Hiroshima and Nagasaki, hit by what would be very small bombs, could receive aid from elsewhere. Now there would be no elsewhere. The utter destruction which would ensue would permit no return to Rich's "quasi-normality".

Rather than taking as authoritative an article published by a single American physicist in Reader's Digest, we would rely upon the resolution adopted virtually unanimously by the (US) National Academy of Sciences (regrettably never published in Nature) on 27 April 1982. We cite only two of its findings: "science offers no prospect of effective defense against nuclear war and mutual destruction, . . . a general nuclear war could kill hundreds of millions and destroy civilization as we know it".

Unanimous endorsement for the entire resolution came in June 1982, from the Executive Committee of the American Physical Society and also from the Academy of Sciences of the Royal Society of Canada.

Eminent physicians have made it absolutely clear that the health care delivery systems would be destroyed by a nuclear bombardment. Death would be widespread. Those who survived the explosion would suffer horribly until their brief post-bomb existence ended.

This was agreed unanimously and documented scientifically by a panel led on the US side by Professor Lowns of Harvard and on the Soviet side by Academician Chazov, Deputy Minister of Health of the
Soviet Union. The panel was televised nationally by the Soviet television network and in the United States by the Public Broadcasting System. Information concerning transcripts is available from the Public Broadcasting System, 609 Fifth Avenue, New York, NY 10017, USA.

\section{ED BARBEAU \\ ERIC FAWCETT \\ TERRY GARDNER \\ BRYDON GOMBAY \\ LEE LORCH \\ DEREK MANCHESTER \\ DeREK PAUL \\ METTA SPENCER \\ LYNN TRAINOR}

(Directors, Science for Peace)

Science for Peace,

Physics Department,

University of Toronto,

Toronto, Canada

VERA Rich's article was not based.on Teller's Reader's Digest article but on a TASS complaint thereat - Editor Nature

\section{Asteroids or comets}

SIR - I appreciate Peter Smith's comments on the rigid anti-catastrophism in geological thinking ( Nature 300, 217; 1982). However, he erred in attributing to Alvarez et al. the idea of a terminal Cretaceous cometary impact.

In fact, those authors postulated asteroid impacts, and argued strongly against the cometary idea, which was suggested by $H$. Urey ( Nature 242, 32, 1973) and more recently by myself (Nature $285,201,1980)$. The two scenarios are fundamentally different; one postulated instant extinction $\left(10^{\circ} \mathrm{yr}\right)$, the other less catastrophic $\left(10^{4} \mathrm{yr}\right)$.

KEN HSU

Eidgenossische Technische Hochschule, Zurich, Switzerland

\section{Alternate culture}

SIR - Both the authors (L. LeShan, $H$. Margenau) and the reviewer (M. Jahoda) of the book Einstein's Space and Van Gogh's Sky ( Nature 25 November 1982, p.385) clearly think that the word "alternate" has the same meaning as "alternative".

Since the battle to preserve the clear and valuable distinction between the meanings of these words has already been lost in the United States, it is probably too late to arrest, in this particular, the slide towards illiteracy in this country. However, your journal enjoys a wide circulation, so that my plea that scientists should occasionally consult their dictionaries may hopefully have some effect.

Department of Mathematics,

D.F. LAWDEN

University of Aston,

Birmingham, UK

\section{Polywater reviewed}

SIR - I have only now managed to obtain Felix Franks' book Polywater, published over a year ago (see Nature 5 November 1981)!.

Even the picture on the cover reveals the intention of the author to show that the story of the investigation of polymeric water can be compared with a burst soap bubble. The book pays little attention to the scientific objective of the investigation proper, to its genesis, or to the results obtained.

In his book, Dr Franks appears arrogant enough to judge and teach, but much of what he writes proves incompatible with such a pretension. In describing the negative aspects of the subject the author exhaustively uses the popular press, including newspapers, while disregarding a number of serious scientific journals. Thus, on page 134 he writes: "Yeland Allen and Peter Kollman stated quite explicitly that the position they now adopted was: 'clearly opposite to that in our original work'. During the whole polywater controversy this was the only (sic) honest statement by a group of workers that their own new findings had forced them to change their mind. Their article in Nature of 22 October, 1971 [ref.2] contains no equivocations, no ambiguities, and no question marks"'

Further on, on page 190 (see also page 140), the author writes, in complete contradiction with reality: "The manner in which Derjaguin wrote off ten years of work and publicity in two sentences (sic) was not easy to accept for those who had followed him, and led to some bitter criticism. Derjaguin, however, was geographically inaccessible. ..."

Inaccessible? Foreign scientists each year visit my department at the Institute of Physical Chemistry of the USSR Academy of Sciences, and we have received as guests Langmuir, La Mer, De Boer, $A$. Zettlemoyer, B. Pethica (twice), Parfitt and many others.

Anyone consulting our publications on the matter ${ }^{3}$ should be convinced that the above accusations are untrue. A study of our papers in Doklady Akademii Nauk (including the English edition) and cited in Nature, covering the detailed analysis of the composition of anomalous columns of water, shows that we did not repeat work carried out by other authors at an earlier date. (Delays in obtaining the final results in our laboratory were connected with problems in gaining access to certain items of equipment such as an electron probe.)

Samples of polywater obtained by about ten different techniques have been subjected to analysis. In a number of cases, $\mathrm{Si}$ and $\mathrm{O}_{2}$ were found to be the only admixtures, proving that those samples were products of leaching of quartz in the water condensate. This is the most reliable confirmation of the need to explain why 